CARDIOVASCULAR MEDICINE

\title{
Heart failure in patients with preserved and deteriorated left ventricular ejection fraction
}

\author{
A Varela-Roman, L Grigorian, E Barge, P Bassante, M G de la Peña, J R Gonzalez-Juanatey
}

Heart 2005;91:489-494. doi: 10.1136/hrt.2003.031922

See end of article for authors' affiliations

.....................

Correspondence to:

Dr J R Gonzalez-Juanatey,

Clinical University

Hospital, Santiago de

Compostela 15706, Spain;

jose.ramon.gonzalez.

juanatey@sergas.es

Accepted 2 June 2004
Objectives: To determine clinical and prognostic differences between preserved and deteriorated systolic function (defined as left ventricular (LV) ejection fractions $\geqslant 50 \%$ and $<50 \%$, respectively) in patients with heart failure satisfying modified Framingham criteria.

Patients and methods: Records were studied of 1252 patients with congestive heart failure (CHF) (mean (SD) age 69.4 (11.7) years; 485 women, $767 \mathrm{men}$ ) who had been admitted to a cardiology service for CHF in the period 1991-2002 and whose LV systolic function had been echocardiographically evaluated within two weeks of admission. Data were collected on the main clinical findings, supplementary examinations, treatment, and duration of hospitalisation. Whether the patient was alive in the spring of 2003 was evaluated by searching the general archives of the hospital and by telephone survey.

Results: LV systolic function was preserved in $39.8 \%$ of patients. Age, female to male sex ratio, and prevalence of atrial fibrillation, valve disease, and other non-ischaemic, non-dilated cardiopathies were all significantly greater in the group with preserved systolic function. New York Heart Association functional class IV, third heart sound, jugular vein congestion, cardiomegaly, radiological signs of lung oedema, pathological $Q$ waves, left bundle branch block, sinus rhythm, ischaemic cardiopathy, and dilated cardiomyopathy were all significantly more prevalent in the group with deteriorated systolic function, as was treatment with angiotensin converting enzyme inhibitors and most other antihypertensive drugs on discharge from hospital. There was no significant difference in survival between the groups with preserved and deteriorated systolic function (either survival regardless of age at admission or in subgroups aged $<75$ and $\geqslant 75$ years at admission). In the whole group, survival rates after one, three, and five years were $84.0 \%, 66.7 \%$, and $50.9 \%$, respectively.

Conclusion: In view of the poor prognosis of patients with CHF with preserved LV systolic function, who are currently treated empirically, it is to be hoped that relevant controlled clinical trials under way will afford information allowing optimisation of their treatment.
C ongestive heart failure (CHF) and chronic atrial fibrillation are the cardiovascular diseases that in recent years have undergone the greatest increase in incidence and prevalence, especially among elderly patients. ${ }^{1-3}$ The Spanish study CARDIOTENS found CHF to account for $25 \%$ of all cardiopathies seen in cardiology services and primary care, its main causes being arterial hypertension and ischaemic cardiopathy. ${ }^{3}$

It is estimated that between $20-50 \%$ of patients with CHF have preserved systolic function (usually defined as a normal left ventricular ejection fraction (LVEF)). ${ }^{5}$ Several studies have reported that in this group there are greater proportions of women, elderly patients, and hypertensive, diabetic, or obese patients than among patients with CHF with deteriorated systolic function and a smaller proportion of patients with prior myocardial infarct. However, deviations from this general pattern have also been reported. These discrepancies are probably attributable largely to differences between the target populations of studies reporting "deviant" and "nondeviant" patterns - in particular, between the general CHF population and the subset of patients with CHF admitted to internal medicine or cardiology services..$^{6-13}$

There has also been considerable diversity among studies as regards the prognosis of patients with CHF with preserved systolic function in relation to those with deteriorated systolic function, and there has been much debate as to the possible causes of any prognostic differences between these two groups. ${ }^{6-13}$ If such prognostic differences do exist, it will be important to determine the chief prognostic factors for each group so as to be able to develop differentiated treatment strategies.

In the work described here we studied the clinical characteristics and long term survival of a large sample of patients with CHF referred to a cardiology service, discriminating between patients with preserved and with deteriorated systolic function.

\section{PATIENTS AND METHODS}

\section{Study groups}

In this prospective observational study we enrolled all patients referred to the cardiology service of the University Clinical Hospital, Santiago de Compostela, who between l January 1991 and 31 December 2002 had completed terms of hospitalisation in this service after referral for CHF, whose left ventricular (LV) systolic function had been evaluated echocardiographically within two weeks of admission, and whose records showed them, in the opinion of the cardiologist authors, to have met modified Framingham criteria for CHF: two or more major criteria (paroxysmal nocturnal dyspnoea, orthopnoea, rales, jugular vein congestion, third heart sound, and radiological signs of pulmonary congestion or cardiomegaly) or one major criterion together with two or more minor criteria (effort dyspnoea, oedema,

\footnotetext{
Abbreviations: CHF, congestive heart failure; CHARM, candesartan in heart failure: assessment of reduction in mortality and morbidity; DIAMOND, Danish investigations of arrhythmia and mortality on dofetilide; LV, left ventricular; LVEF, left ventricular ejection fraction; NYHA, New York Heart Association
} 
hepatomegaly, and pleural effusion). Of the 1659 patients admitted for $\mathrm{CHF}$, the above inclusion criteria were met by $1252(75.5 \%)$; the other 407 were excluded either because an echocardiographic study was lacking or because its quality was too poor for proper evaluation of ventricular function. There were no significant differences between the included and excluded groups in any of the non-echocardiographic variables discussed below.

Of the 1252 patients enrolled in the study, 309 had a previous diagnosis of CHF and 998 were being admitted to hospital for CHF for the first time. Once enrolled in the study, patients were assigned to one of two groups on the basis of whether their systolic function was preserved, the criterion for preserved function being an echocardiographically determined LVEF of at least $50 \%$.

Echocardiograms were recorded in accordance with the guidelines of the American Society of Echocardiography. Ventricular volumes were obtained from apical four chamber views by the mean area $\times$ length method. LVEF (\%) was calculated as $100 \times(\mathrm{LV}$ end diastolic volume $-\mathrm{LV}$ end systolic volume)/LV end diastolic volume. All measurements were repeated for four to six successive heart beats and were averaged.

\section{Data collected}

For all patients in the study, data were collected on the main clinical findings, supplementary examinations, treatment, and duration of hospitalisation. In the case of patients admitted more than once during the study period, the only admission considered was the first during which systolic function had been echocardiographically evaluated. Information on the patients' current situation and mortality data were obtained by searching the general archives of the hospital and by means of a telephone survey carried out in April and May 2003.

\section{Aetiological evaluation}

Ischaemic cardiopathy was diagnosed if any of the following criteria were met: a recorded diagnosis of ischaemic cardiopathy, prior admission for some acute coronary event (acute myocardial infarct or unstable angina), prior surgical or percutaneous myocardial revascularisation, the presence of pathological Q waves in the ECG obtained during hospitalisation, and coronary images showing $\geqslant 50 \%$ stenosis of at least one coronary vessel. Valve disease was diagnosed if it had been previously diagnosed or if it was indicated by echocardiographic or catheterisation studies (note, however, that the study did not include patients who had been admitted to the cardiology service because of severe valve disease with CHF diagnosed only as secondary to the valve pathology). Arterial hypertension was diagnosed if it had been previously diagnosed or if the patient had been taking or needed antihypertensive drugs to control blood pressure. Dilated cardiomyopathy was diagnosed if the patient had deteriorated systolic function and a dilated LV but no evidence of ischaemic cardiopathy, valve disease, or arterial hypertension.

\section{Statistical analysis}

Data for categorical or dichotomous variables are expressed as percentages and were compared by a $\chi^{2}$ test or Fisher's exact test. Data for continuous variables are expressed as mean (SD) and were compared by Student's $t$ tests. Survival curves for subgroups and for the whole sample were estimated by the Kaplan-Meier method and those for groups with preserved and deteriorated systolic function were compared by the two sample log rank test. Factors with independent significant association with survival were identified by Cox's proportional hazards model in a backward

\begin{tabular}{|c|c|}
\hline Variable & $\begin{array}{l}\text { Mean (SD) or } \\
\text { number }(\%)\end{array}$ \\
\hline Age (years) & $69.4(11.7)$ \\
\hline$<75$ & $838(66.9 \%)$ \\
\hline$\geqslant 75$ & $414(33.1 \%)$ \\
\hline \multicolumn{2}{|l|}{ Sex } \\
\hline Men & $767(61.3 \%)$ \\
\hline Women & 485 (38.7\%) \\
\hline Time in hospital (days) & $14.4(12.1)$ \\
\hline \multicolumn{2}{|l|}{ Risk factors } \\
\hline Arterial hypertension & $693(55.4 \%)$ \\
\hline Hyperlipidaemia & $419(33.5 \%)$ \\
\hline Diabetes mellitus & $335(26.8 \%)$ \\
\hline Smoking & $390(31.2 \%)$ \\
\hline \multicolumn{2}{|l|}{ Underlying cardiopathy } \\
\hline Ischemic cardiopathy & 616 (49.2\%) \\
\hline Valve disease & $260(20.8 \%)$ \\
\hline Dilated cardiomyopathy & $116(9.2 \%)$ \\
\hline Other & $260(20.8 \%)$ \\
\hline \multicolumn{2}{|l|}{ Clinical signs } \\
\hline NYHA class IV & $522(41.7 \%)$ \\
\hline Rales & 958 (76.5\%) \\
\hline Jugular vein congestion & $562(44.9 \%)$ \\
\hline Hepatomegaly & $292(23.3 \%)$ \\
\hline Third heart sound & 165 (13.2\%) \\
\hline \multicolumn{2}{|l|}{ Radiographic signs } \\
\hline Cardiomegaly & 994 (79.4\%) \\
\hline Flow redistribution & 808 (64.5\%) \\
\hline Interstitial oedema & $623(49.8 \%)$ \\
\hline Alveolar oedema & $152(12.1 \%)$ \\
\hline Pleural effusion & 243 (19.4\%) \\
\hline \multicolumn{2}{|l|}{ ECG signs } \\
\hline Sinus rhythm & 675 (53.9\%) \\
\hline Atrial fibrillation & $424(33.9 \%)$ \\
\hline Pathological $Q$ waves & $260(20.8 \%)$ \\
\hline LBBB & 196 (15.7\%) \\
\hline \multicolumn{2}{|l|}{ Echocardiography } \\
\hline LVEF $<50 \%$ & $754(60.2 \%)$ \\
\hline LVEF $\geqslant 50 \%$ & $498(39.8 \%)$ \\
\hline \multicolumn{2}{|l|}{ Drug treatment } \\
\hline Digoxin & $386(30.8 \%)$ \\
\hline Diuretics & 948 (75.7\%) \\
\hline ACE inhibitors & $785(62.7 \%)$ \\
\hline ARB & $65(5.2 \%)$ \\
\hline Spironolactone & $162(12.9 \%)$ \\
\hline Nitrates & 545 (43.5\%) \\
\hline Hydralazine & $59(4.7 \%)$ \\
\hline Vasodilators & 79 (6.3\%) \\
\hline Calcium antagonists & $237(18.9 \%)$ \\
\hline$\beta$ Blockers & $351(28.0 \%)$ \\
\hline Amiodarone & $199(15.9 \%)$ \\
\hline Antiplatelet agents & 710 (56.7\%) \\
\hline Anticoagulants & $336(26.8 \%)$ \\
\hline \multicolumn{2}{|c|}{$\begin{array}{l}\text { ACE, angiotensin converting enzyme; ARB, angiotensin II } \\
\text { receptor blocker; LBBB, left bundle branch block; LVEF, lef } \\
\text { ventricular ejection fraction; NYHA, New York Heart } \\
\text { Association. }\end{array}$} \\
\hline
\end{tabular}

stepwise regression analysis with age, sex, New York Heart Association (NYHA) functional class IV, third heart sound, cardiomegaly, alveolar oedema, hypertension, hyperlipaemia, diabetes, smoking, ischaemic cardiopathy, and EF as independent variables, followed by a secondary Cox analysis in which the independent variables were those identified as significant in the first analysis plus EF. The resulting regression coefficients were used to estimate relative risks and the corresponding 95\% confidence intervals. The validity of the assumption of proportional hazards was supported by the results of calculating log-log survival plots for each variable with age and sex controlled. The criterion for significance was $\mathrm{p}<0.05$. 


\begin{tabular}{|c|c|c|c|}
\hline \multirow[b]{2}{*}{ Variable } & \multicolumn{2}{|l|}{ LVEF } & \multirow[b]{2}{*}{$\mathrm{p}$ Value } \\
\hline & $<50 \%(n=754)$ & $\geqslant 50 \%(n=498)$ & \\
\hline Age (years) & $67.4(12.2)$ & $72.3(10.2)$ & $<0.0001$ \\
\hline \multicolumn{4}{|l|}{ Sex } \\
\hline Men & $522(69.2 \%)$ & $245(49.2 \%)$ & $<0.0001$ \\
\hline Women & $232(30.8 \%)$ & $253(50.8 \%)$ & \\
\hline Time in hospital (days) & $15.0(12.0)$ & $13.6(12.3)$ & 0.047 \\
\hline \multicolumn{4}{|l|}{ Risk factors } \\
\hline Arterial hypertension & 389 (51.6\%) & $304(61.0 \%)$ & $<0.001$ \\
\hline Hyperlipaemia & $256(34.0 \%)$ & $163(32.7 \%)$ & 0.66 \\
\hline Diabetes mellitus & $210(27.9 \%)$ & $125(25.1 \%)$ & 0.250 \\
\hline Smoking & $269(35.7 \%)$ & $121(24.3 \%)$ & $<0.0001$ \\
\hline \multicolumn{3}{|l|}{ Underlying cardiopathy } & $<0.0001$ \\
\hline Ischaemic cardiopathy & 409 (54.2\%) & $207(41.6 \%)$ & \\
\hline Valve disease & $95(12.6 \%)$ & $165(33.1 \%)$ & \\
\hline Dilated cardiomyopathy & $116(15.4 \%)$ & 0 & \\
\hline Other & $134(17.8 \%)$ & $126(25.3 \%)$ & \\
\hline \multicolumn{4}{|l|}{ Clinical signs } \\
\hline NYHA class IV & $332(44.0 \%)$ & 190 (38.2\%) & 0.017 \\
\hline Jugular vein congestion & $362(48.0 \%)$ & $200(40.2 \%)$ & 0.030 \\
\hline Third heart sound & 149 (19.8\%) & $16(3.2 \%)$ & $<0.0001$ \\
\hline \multicolumn{4}{|l|}{ Radiographic signs } \\
\hline Cardiomegaly & 613 (81.3\%) & 381 (76.5\%) & 0.005 \\
\hline Alveolar oedema & 118 (15.6\%) & $34(6.8 \%)$ & $<0.0001$ \\
\hline \multicolumn{4}{|l|}{ ECG signs } \\
\hline Sinus rhythm & 445 (59.0\%) & $230(46.2 \%)$ & $<0.0001$ \\
\hline Atrial fibrillation & $232(30.8 \%)$ & $192(38.6 \%)$ & 0.0049 \\
\hline Pathological Q wave & 191 (25.3\%) & $69(13.9 \%)$ & $<0.0001$ \\
\hline LBBB & 159 (21.1\%) & $37(7.4 \%)$ & $<0.0001$ \\
\hline \multicolumn{4}{|l|}{ Drug treatment } \\
\hline Digoxin & $271(36.0 \%)$ & 115 (23.1\%) & $<0.0001$ \\
\hline Diuretics & 618 (82.0\%) & $330(66.3)$ & $<0.0001$ \\
\hline ACE inhibitors & $534(70.8)$ & $251(50.4 \%)$ & $<0.0001$ \\
\hline ARB & $40(5.3 \%)$ & 25 (5.0\%) & 0.842 \\
\hline Spironolactone & $121(16.0 \%)$ & $41(8.2 \%)$ & 0.0007 \\
\hline Nitrates & 361 (47.9\%) & $184(36.9 \%)$ & 0.0004 \\
\hline Hydralazine & $43(5.7 \%)$ & $16(3.2 \%)$ & 0.056 \\
\hline Vasodilators & $50(6.6 \%)$ & $29(5.8 \%)$ & 0.624 \\
\hline Calcium antagonists & $82(10.9 \%)$ & $155(31.1 \%)$ & $<0.0001$ \\
\hline$\beta$ Blockers & $233(30.9 \%)$ & 118 (23.7\%) & 0.011 \\
\hline Amiodarone & 130 (17.3\%) & $69(13.9 \%)$ & 0.131 \\
\hline Antiplatelet agents & $452(60 \%)$ & 258 (51.8\%) & 0.007 \\
\hline Anticoagulants & 195 (25.9\%) & $141(28.3 \%)$ & 0.441 \\
\hline
\end{tabular}

\section{RESULTS}

\section{Characteristics of the whole sample}

The sample comprised 1252 patients, mean (SD) age 69.4 (11.7) years (range 16-98 years), of whom 485 were women $(38.7 \%)$ and 767 men $(61.3 \%)$. The duration of hospitalisation was 14.4 (12.1) days. The most common CHF risk factor was systemic arterial hypertension, which 693 patients (55.4\%) had. The most common underlying heart condition

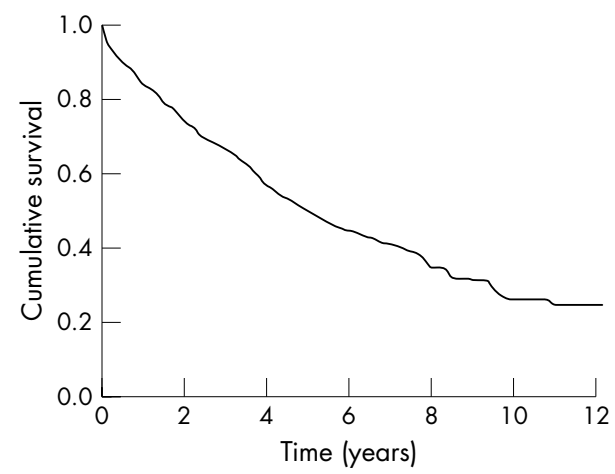

Figure 1 Kaplan-Meier survival curve of the whole sample. was ischaemic cardiomyopathy, which was diagnosed in 616 patients $(49.2 \%)$. Table 1 lists the patients' chief clinical characteristics and the drugs prescribed on discharge.

\section{Characteristics of the groups defined by systolic function}

Systolic function was deteriorated in 754 patients $(60.2 \%)$ and preserved in the other 498 (39.8\%). Table 2 summarises the characteristics of these two groups. Age at admission, female to male sex ratio and the prevalence of atrial fibrillation, valve disease, and other non-ischaemic, nondilated cardiopathies were all significantly greater in the group with preserved function. NYHA functional class IV, third heart sound, jugular vein congestion, cardiomegaly, radiological signs of pulmonary oedema, pathological Q waves, left bundle branch block, sinus rhythm, ischaemic cardiopathy, and dilated cardiomyopathy were all more prevalent in the group with deteriorated function. On average, patients with deteriorated function were hospitalised for significantly longer (15.0 (12.0) days $v$ 13.6 (12.3) days, $\mathrm{p}=0.047$ ). There were also significant differences between the two groups in the medication prescribed on discharge from hospital: angiotensin converting enzyme inhibitors and most other antihypertensive drugs were prescribed significantly more often to patients with deteriorated systolic function (table 2). 
Table 3 Association between survival after five years and various clinical variables

\begin{tabular}{|c|c|c|}
\hline Variable & $\begin{array}{l}5 \text { year survival } \\
(\%)\end{array}$ & p Value \\
\hline Age (years) & & $<0.0001$ \\
\hline$<75$ & 58.1 & \\
\hline$\geqslant 75$ & 34.6 & \\
\hline Sex & & 0.16 \\
\hline Men & 51.0 & \\
\hline Women & 49.6 & \\
\hline NYHA class IV & & 0.02 \\
\hline No & 53.2 & \\
\hline Yes & 46.3 & \\
\hline Third heart sound & & 0.68 \\
\hline No & 51.1 & \\
\hline Yes & 53.5 & \\
\hline Rales & & 0.02 \\
\hline No & 60.2 & \\
\hline Yes & 48.4 & \\
\hline Jugular vein congestion & & 0.04 \\
\hline No & 53.6 & \\
\hline Yes & 48.6 & \\
\hline Hepatomegaly & & 0.13 \\
\hline No & 51.3 & \\
\hline Yes & 50.5 & \\
\hline \multicolumn{3}{|l|}{ Radiographic signs } \\
\hline Cardiomegaly & & 0.31 \\
\hline No & 59.3 & \\
\hline Yes & 49.8 & \\
\hline Alveolar oedema & & $<0.0001$ \\
\hline No & 53.2 & \\
\hline Yes & 35.5 & \\
\hline \multicolumn{3}{|l|}{ ECG signs } \\
\hline Sinus rhythm & & 0.24 \\
\hline No & 47.7 & \\
\hline Yes & 52.6 & \\
\hline Atrial fibrillation & & 0.33 \\
\hline No & 50.4 & \\
\hline Yes & 50.3 & \\
\hline LBBB & & 0.86 \\
\hline No & 64.0 & \\
\hline Yes & 49.5 & \\
\hline \multicolumn{3}{|l|}{ Risk factors } \\
\hline Arterial hypertension & & 0.07 \\
\hline No & 52.6 & \\
\hline Yes & 50.0 & \\
\hline Hyperlipaemia & & 0.96 \\
\hline No & 51.0 & \\
\hline Yes & 52.0 & \\
\hline Diabetes mellitus & & $<0.0001$ \\
\hline No & 55.8 & \\
\hline Yes & 37.1 & \\
\hline Smoking & & 0.33 \\
\hline No & 51.5 & \\
\hline Yes & 52.3 & \\
\hline Underlying cardiopathy & & $<0.0001$ \\
\hline Ischaemic cardiopathy & 47.9 & \\
\hline Valve disease & 41.9 & \\
\hline Dilated cardiomyopathy & 67.7 & \\
\hline Others & 57.3 & \\
\hline
\end{tabular}

\section{Survival}

Among the 1133 patients for whom reliable survival data were obtainable (90.5\% of the total 1252), the mean (SD) time elapsed since hospitalisation was 3.0 (2.7) years (range 0-12.3 years). By April and May 2003, 668 had died (59.0\%). The death rates after one, three, and five years were $16.0 \%$, $33.3 \%$, and $49.1 \%$, respectively (fig 1 shows the survival curve of the whole sample); median survival time was 5.1 (0.4) years (95\% confidence interval 4.3 to 5.9 years).

Table 3 lists the results of univariate analyses carried out to determine the effects several variables on survival. In order of decreasing significance, age $(\mathrm{p}<0.0001)$, diabetes $(p<0.0001)$, alveolar oedema $(p<0.0001)$, jugular vein congestion $(p=0.04)$, NYHA class IV $(p=0.02)$, and rales $(p=0.02)$ were all associated with poorer prognosis.
Table 4 Variables influencing the survival of patients with congestive heart failure (results of multivariate analysis)

\begin{tabular}{llll}
\hline Variable & RR & $\mathbf{9 5 \%} \mathbf{C l}$ & $\mathbf{p ~ V a l u e ~}$ \\
\hline Age & 1.65 & 1.45 to 1.87 & $<0.0001$ \\
Alveolar oedema & 1.52 & 1.16 to 1.99 & 0.002 \\
Jugular vein congestion & 1.28 & 1.05 to 1.56 & 0.014 \\
Diabetes mellitus & 1.31 & 1.05 to 1.62 & 0.016 \\
Aetiology & 0.90 & 0.83 to 0.98 & 0.019 \\
\hline Cl, confidence interval; RR, relative risk. & & \\
\hline
\end{tabular}

Aetiology also affected survival $(\mathrm{p}<0.0001)$ : ischaemic cardiopathy and valve disease were related with lower survival time than dilated cardiomyopathy and cardiopathy other than dilated cardiomyopathy, ischaemic cardiopathy, or valve disease. Multivariate analysis showed survival to be significantly influenced by age, alveolar oedema, jugular vein congestion, diabetes mellitus, and aetiology (table 4).

LVEF had no significant effect on survival even after adjustment for the predictors listed above $(p=0.798)$. In keeping with this, the survival curves of the two groups (fig 2) do not differ significantly. At one, three, and five years after hospitalisation, respectively, $20.3 \%, 39.9 \%$, and $54.7 \%$ of patients with deteriorated systolic function and $17.2 \%, 33.9 \%$, and $44.2 \%$ of patients with preserved systolic function had died. Survival also did not differ significantly between the two groups within either of the two age groups distinguished $(<75$ and $\geqslant 75$ years) (fig 3$)$.

\section{DISCUSSION}

Despite considerable progress in the prevention, diagnosis, and treatment of CHF in recent decades, mortality and morbidity caused by this disease remain high among both hospitalised patients and patients attending primary care centres. ${ }^{6} \mathrm{CHF}$ is one of the main causes of admission to and death in hospital. ${ }^{14}{ }^{15}$ In terms of the traditional classification of CHF based on systolic and diastolic dysfunction, the prevalence of diastolic dysfunction appears to have increased. Although the LV diastolic function of many patients who are admitted to hospital for CHF is not evaluated when they are found to have normal LV systolic function, and their CHF should therefore be strictly classified as being caused by preserved systolic function rather than diastolic dysfunction, ${ }^{16-18}$ it has been reported that practically all patients with CHF with preserved systolic function do have altered diastolic function. ${ }^{7}$ Studies of the differences in clinical characteristics, prognosis, and the factors determining prognosis between

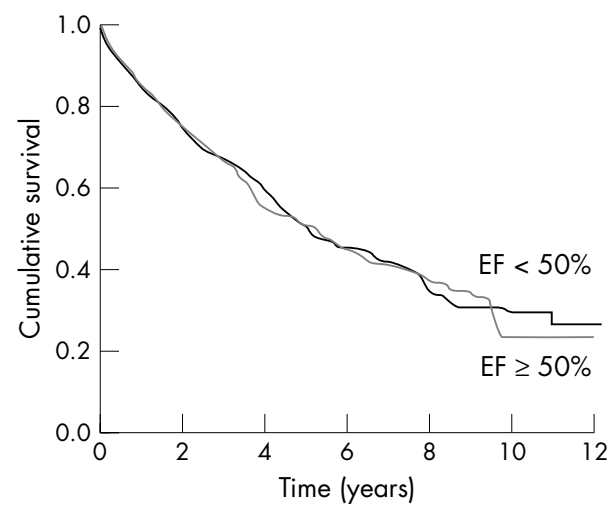

Figure 2 Kaplan-Meier survival curves of the groups with preserved and deteriorated left ventricular systolic function. Differences were not significant. EF, ejection fraction. 


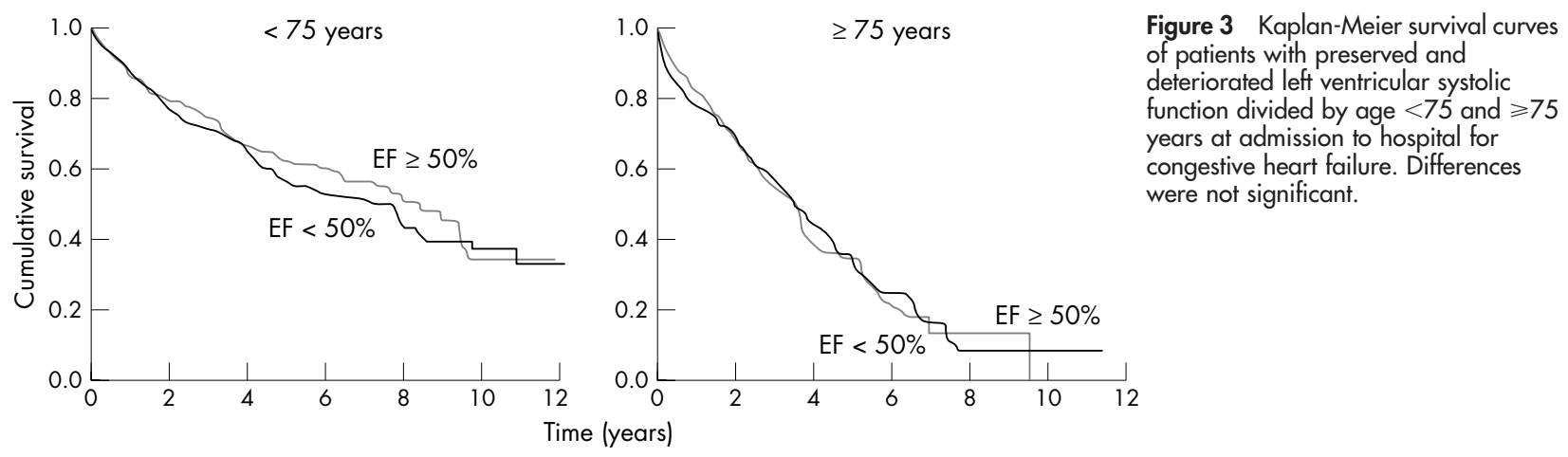

patients with CHF with preserved and those with deteriorated systolic function have not all reached the same conclusions, ${ }^{6-13}$ but their discrepancies are probably attributable to differences in the methods used to evaluate cardiac function, the duration of follow up, and in particular, as noted in above, the target population (patients hospitalised in cardiology or internal medicine services versus patients attending primary care services). The generality of our results may have been limited by restriction of our study population to patients with CHF admitted to our university hospital cardiology service (in particular, exclusion of patients admitted to the internal medicine service may have led to our sample being younger and having a greater prevalence of ischaemic cardiopathy than if patients from both services had been studied). However, this limitation, which facilitated rapid echocardiographic evaluation of LV function by specialised personnel, also lends greater precision to the results obtained for the population so defined, which constitutes an important subset of patients with CHF.

In this study the death rate was higher than in recent clinical trials, ${ }^{19-22}$ possibly because of the younger average age of the patients in these trials or differences in treatment strategy. Death was related to the same factors as in other clinical series ${ }^{23}{ }^{24}$ : age, diabetes, underlying cardiopathy, and signs of systemic or pulmonary congestion (jugular vein congestion and radiological signs of alveolar oedema).

The criterion for normal systolic function in this study was LVEF $\geqslant 50 \%$, the threshold usually used in work in this area. Although LVEF is not a constant characteristic of a given patient, depending as it does on the work required of the heart, this "normal" variation was probably limited by measuring LVEF of all the patients in this study while they were hospitalised, within two weeks of admission. The echocardiographic method used to measure LVEF, though imperfect (two volumes are measured with no better than moderate reproducibility), is sufficiently precise for our purpose.

With the patient groups defined on the basis of the above LVEF criterion, our results agree with those of the DIAMOND (Danish investigations of arrhythmia and mortality on dofetilide) study of patients admitted for CHF to 34 Danish hospitals ${ }^{25}$ in that patients with preserved systolic function were older, more were women, and fewer had ischaemia than patients with systolic dysfunction. In the DIAMOND study survival decreased with increasing deterioration of systolic function, especially among younger patients with ischaemic cardiopathy, whereas we did not find patients with preserved systolic function to have a better prognosis than those with systolic dysfunction (either in the whole group or within the two age groups that were distinguished). This difference may be attributed to DIAMOND having used a more sensitive measure of systolic function (echocardiographic wall motion index).
The association between preservation of systolic function and female sex among patients with CHF has been observed in practically all studies in this area, including one in which the patients had developed CHF after myocardial infarction. ${ }^{26}$ Although it has been suggested that this association may result from the smaller infarct size of women or from differences between men and women in LV remodelling in response to pressure overload, ${ }^{27}$ further research is necessary to clarify this issue.

Reported annual death rates among patients who have at some time been hospitalised for CHF with preserved systolic function have ranged from $1.3-17.5 \%,{ }^{911} 122930$ probably because of differences between studies in the age of the patients and the severity of the disease. As in our study, however, in most of these studies the practical difficulties of follow up have prevented the collection of data on the causes of death of these patients; it is therefore not known whether their deaths were related to their greater age and greater prevalence of arterial hypertension by including a greater proportion of deaths from non-cardiac vascular events. ${ }^{31}$ Morbidity rates, as measured by the incidence of further periods of hospitalisation, are not significantly influenced by whether the patient has preserved or deteriorated systolic function.

Although many authors have discussed possible physiopathological bases for the treatment of CHF with preserved systolic function, there is little solid scientific evidence on which to base treatment. ${ }^{32} 33$ The results of clinical trials of angiotensin converting enzyme inhibitors, angiotensin II receptor blockers, and $\beta$ blockers are eagerly awaited. In the CHARM (candesartan in heart failure: assessment of reduction in mortality and morbidity)-Preserved trial, ${ }^{34}$ candesartan was not significantly better than placebo in preventing the primary adverse outcome (death caused by cardiovascular disease or admission to hospital for CHF) among patients with CHF and LVEF $>40 \%$, although fewer patients taking candesartan were admitted for CHF. ${ }^{10}$

Until more information is provided by the studies that are under way, treatment of CHF with preserved systolic function should be aimed at controlling blood pressure (both in the acute phase of the disease and in the long term), preventing tachycardia, maintaining sinus rhythm, alleviating ischaemia, and attempting to regress the CHF associated alterations of cardiac structure and function (LV hypertrophy and myocardial fibrosis).

\section{Conclusions}

The death rate among patients hospitalised in our cardiology service for CHF is high-higher than in recent large clinical trials. A large proportion of these patients (about 40\%) have preserved systolic function. This group of patients with CHF with preserved systolic function has an older average age, a larger proportion of women, and a larger proportion of 
hypertensive patients than the group of patients with CHF with systolic dysfunction, but the two groups did not have significantly different survival rates (nor did the corresponding subgroups of the age groups considered). These findings reinforce the need for new preventive strategies and new treatments specifically targeted at patients with CHF with preserved systolic function.

\section{Authors' affiliations}

A Varela-Roman, L Grigorian, E Barge, P Bassante, M G de la Peña, J R Gonzalez-Juanatey, Clinical University Hospital, Santiago de Compostela, Spain

\section{REFERENCES}

1 Havranek EP, Masoudi FA, Westfall KA, et al. Spectrum of heart failure in older patients: results from the national heart failure project. Am Heart $J$ 2002;143:12-7.

2 Mosterd A, Hoes AW, de Bruyne MC, et al. Prevalence of heart failure and left ventricular dysfunction in the general population. The Rotterdam study. Eur Heart J 1999;20:447-55.

3 González-Juanatey JR, Alegría E, Lozano JV, et al. Impacto de la hipertensión en las cardiopatías en España. Estudio CARDIOTENS 1999. Rev Esp Cardiol 2001;54:139-49.

4 García-Acuña JM, González-Juanatey JR, Alegría E, et al. La fibrilación auricular permanente en las enfermedades cardiovasculares en España. Estudio CARDIOTENS 1999. Rev Esp Cardiol 2002;55:943-52.

5 Hogg K, Swedberg K, McMurray J. Heart failure with preserved left ventricular systolic function. epidemiology, clinical characteristics and prognosis. J Am Coll Cardiol 2004:43:317-27.

6 Jessup M, Brozena S. Heart failure. N Engl J Med 2003;348:2007-18.

7 Redfield MM, Jacobsen SJ, Burnett JC Jr, et al. Burden of systolic and diastolic ventricular dysfunction in the community: appreciating the scope of the heart failure epidemic. JAMA 2003;289:194-202.

8 Ahmed A, Roseman JM, Duxbury AS, et al. Correlates and outcomes of preserved left ventricular systolic function among older adults hospitalized with heart failure. Am Heart J 2002;144:365-72.

9 Senni M, Redfield MM. Heart failure with preserved systolic function: a different natural history. J Am Coll Cardiol 2001;38:1277-82.

10 Yusuf S, Pfeffer MA, Swedberg K, for the CHARM Investigators and Committees, et al. Effects of candesartan in patients with chronic heart failure and preserved left-ventricular ejection fraction: the CHARM-preserved trial. Lancet 2003;362:777-81.

11 Vasan RS, Larson MG, Benjamin EJ, et al. Congestive heart failure in subjects with normal versus reduced left ventricular ejection fraction. J Am Coll Cardiol 1999;33:1948-55.

12 Senni M, Tribouilloy CM, Rodeheffer RJ, et al. Congestive heart failure in the community: a study of all incident cases in Olmsted County, Minnesota, in 1991. Circulation 1998;98:2282-9.

13 Varela-Román A, González-Juanatey JR, Basante P, et al. Clinical characteristics and prognosis of hospitalised inpatients with heart failure and preserved or reduced left ventricular ejection fraction. Heart 2002;88:249-54

14 Cowie MR, Fox KF, Wood DA, et al. Hospitalisation of patients with heart failure: a population-based study. Eur Heart J 2002;23:877-85.
15 La insuficiencia cardíaca en los servicios de medicina interna (estudio SEMIIC). Grupo de Trabajo de Insuficiencia Cardíaca de la Sociedad Española de Medicina Interna (SEMI). Med Clin (Barc) 2002;1 18:605-10.

16 Zile MR, Brutsaert DI. New concepts in diastolic dysfunction and diastolic heart failure. II. Casual mechanisms and treatment. Circulation 2002;105:1503-8.

17 Zile MR, Gaasch WH, Carroll JD, et al. Heart failure with normal ejection fraction: is measurement of diastolic function necessary to make the diagnosis of diastolic heart failure? Circulation 2001;104:779-85.

18 Vasan RS, Levy D. Defining diastolic heart failure: a call for standardized diagnostic criteria. Circulation 2000;101:2118-21.

19 Cohn JN, Tognoni G. A randomized trial of the angiotensin-receptor blocker valsartan in chronic heart failure. Valsartan heart failure trial investigators. N Engl J Med 2001;345:1667-75.

20 CIBIS II Investigators. The cardiac insufficiency bisoprolol study II (CIBIS II): a randomised trial. Lancet 1999;353:9-13.

21 MERIT-HF Investigators. Effect of metoprolol CR/XL in chronic heart failure: metoprolol CR/XL randomised trial in congestive heart failure (MERIT-HF). Lancet 1999:353:2001-7.

22 Packer $M$, Coats AJ, Fowler MB, et al. Effect of carvedilol on survival in severe chronic heart failure. N Engl J Med 2001;344:1651-8.

23 Blackledge HM, Tomlinson J, Squire IB. Prognosis for patients newly admitted to hospital with heart failure: survival trends in 12220 index admissions in Leicestershire 1993-2001. Heart 2003:89:615-20.

24 Bouvy ML, Heerdink ER, Leufkens HGM, et al. Predicting mortality in patients with heart failure: a pragmatic approach. Heart 2003;89:605-9.

25 Gustafsson F, Torp-Pedersen C, Brendorp B, et al, for the DIAMOND study group. Long-term survival in patients hospitalized with congestive heart failure: relation to preserved and reduced left ventricular systolic function. Eur Heart J 2003;24:863-70.

26 Hellermann JP, Jacobsen SJ, Reeder GS, et al. Heart failure after myocardial infarction: prevalence of preserved left ventricular systolic function in the community. Am Heart J 2003;145:742-8.

27 Kitzman DW. Heart failure with normal systolic function. Clin Geriatr Med 2000;16:489-512.

28 Weinberg EO, Thienelt CD, Katz SE, et al. Gender differences in molecular remodelling in pressure overload hypertrophy. J Am Coll Cardiol 1999;34:264-73

29 Vasan RS, Benjamin EJ, Levy D. Prevalence, clinical features and prognosis of diastolic heart failure: an epidemiologic perspective. J Am Coll Cardiol 1995;26:1565-74.

30 Setaro JF, Soufer R, Remetz MS, et al. Long-term outcome in patients with congestive heart failure and intact left ventricular systolic performance. Am J Cardiol 1992;69: 1212-6.

31 Guidelines Committee. 2003 European Society of Hypertension-European Society of Cardiology guidelines for the management of arterial hypertension. J Hypertens 2003;21:1011-53.

32 American College of Cardiology, American Heart Association. ACC/AHA guidelines for the evaluation and management of chronic heart failure in the adult: executive summary: a report of the American College of Cardiology/ American Heart Association task force on practice guidelines. J Am Coll Cardiol 2001;38:2101-13.

33 Task Force Report. Guidelines for the diagnosis and treatment of chronic heart failure. European Society of Cardiology. Eur Heart J 2001;22:1527-60.

34 McMurray J, Ostergren J, Pfeffer M, on behalf of the CHARM Committees and Investigators, et al. Clinical features and contemporary management of patients with low and preserved ejection fraction heart failure: baseline characteristics of patients in the candesartan in heart failure-assessment of reduction in mortality and morbidity (CHARM) programme. Eur J Heart Fail 2003;5:261-70.

\section{ELECTRONIC PAGES}

\section{Heart Online case reports: www.heartjnl.com}

? he following electronic only articles are published in conjunction with this issue of Heart.

\section{Right ventricular infarction complicated by right to left shunting through an atrial septal defect: successful treatment with an Amplatzer septal occluder \\ S Bassi, R Amersey, R Andrews}

A 68 year old woman presented with right ventricular myocardial infarction complicated by refractory hypoxaemia. She was found to have a significant right to left shunt at the atrial level through a previously undiagnosed ostium secundum atrial septal defect. Percutaneous closure of the atrial septal defect with an Amplatzer septal occluder resulted in prompt improvement in her oxygenation and clinical state. Such closure should be considered for patients with right ventricular infarction and refractory hypoxaemia caused by a right to left interatrial shunt.
(Heart 2005;91:e28) www.heartjnl.com/cgi/content/full/9l/ $4 / \mathrm{e} 28$

\section{Superior vena cava syndrome caused by a pseudoaneurysm of the ascending aorta}

T Vydt, J Coddens, F Wellens

Pseudoaneurysm of the ascending aorta is a well known complication after aortic root surgery. A case of a large pseudoaneurysm is reported, seen as a superior vena cava syndrome, a very rare clinical presentation. Perioperative transoesophageal echocardiography showed the presence of a large pseudoaneurysm starting from the left coronary ostium implantation.

(Heart 2005;91:e29) www.heartjnl.com/cgi/content/full/91/ 4/e29 